University for Business and Technology in Kosovo

UBT Knowledge Center

UBT International Conference

2018 UBT International Conference

Oct 27th, 1:30 PM - 3:00 PM

\title{
Cranial Injuries with Screwdriver - UCCK
}

\author{
Besnik Elshani \\ University for Business and Technology, besnik.elshani@ubt-uni.net \\ Salih Krasniqi \\ University Clinical Centre of Kosovo
}

Follow this and additional works at: https://knowledgecenter.ubt-uni.net/conference

Part of the Medicine and Health Sciences Commons

\section{Recommended Citation}

Elshani, Besnik and Krasniqi, Salih, "Cranial Injuries with Screwdriver - UCCK" (2018). UBT International Conference. 356.

https://knowledgecenter.ubt-uni.net/conference/2018/all-events/356

This Event is brought to you for free and open access by the Publication and Journals at UBT Knowledge Center. It has been accepted for inclusion in UBT International Conference by an authorized administrator of UBT Knowledge Center. For more information, please contact knowledge.center@ubt-uni.net. 


\title{
Cranial Injuries with Screwdriver - UCCK
}

\author{
(University Clinical Centre of Kosovo) \\ Besnik Elshani ${ }^{1}$, Salih Krasniqi ${ }^{1}$ \\ Prishtina, 10000
}

\begin{abstract}
In terms of anatomy, the human body is very complicated. Moreover it represents an entire structure of a human being. What makes it very unique is the way of its composition; different and diverse types of cells and everything is connected to everything else. A combination of cells create tissues which then those tissues create the organ systems. Therefore, in this study presentation I will present the importance of brain as an organ, with a focus on the cranial Injury with a screwdriver. One of the most important and complicated parts of the body is the human head.
\end{abstract}

Keywords: Skull, Cranial, Brain, Cells

\section{Introduction}

Those organs system make the human body to function properly and they grow (age) within years. It is located in the upper portion and certainly is represented by a unique face, thus, maintained by the (inside) skull and the brain is located within the skull. Skull plays an important role, because it directly protects the human brain, which, results to be the most complicated and fascinating organ in the human body. Without brain nothing would function properly, indeed.

\subsection{Introduction of the brain \& Cranial Injury}

To start with, the human brain is consisted of the frontal lobe (front), the parietal lobe (middle) and the occipital lobe (on the back - (end) of the brain) and each lobe has its own role forcing the brain to maintain its health and manage other organs. Nevertheless, it is the central organ of the nervous system and connecting with the spinal cord (back of the human body) it is known otherwise as the central nervous system of the human body. Besides the cerebral lobes mentioned earlier, the nervous system is made of the cerebrum, cerebellum and last but not least, the brainstem. Being the most important organ is not an easy duty. Numerous of processes, maybe billions of processes are controlled by the brain itself, followed with the body activities, precise coordination of information, receiving and delivering that information properly and controlling the senses of a human, followed with good decision making skills as well [1].

Secondly, brain protection is highly studied and experimented, due to the fact that being the most important and diverse organ, the upper portion needs extra protection [2]. The skull bones of the head serve as a good prevention from the brain being harmed accidentally - physically. However, except physical injuries that might happen to the brain and the human body in general, 
there are also certain types of traumas that might directly harm the brain. Such traumas are known as Cranial Traumas (most commonly affects the adults for specific reasons). Patients who already suffer from such traumas are more likely to have had brain injuries which could also affect other (important) organs that serve to maintain the stability of the body itself [1].

Thirdly, re-stating the fact that brain can be damaged physically is probably one of the most common cases in today's world and / or society. Additionally, head injuries in general include brain, scalp or skull injury. Despite the fact of what really may cause a head injury which may cause skull fractures and other undesired wounds, the consequences can be seen either immediately after the injury or later on in life, depending the fact of the severity of the injury itself [3]. Head injuries are most commonly caused by everyday life situations, such as car accidents (including motor vehicles as well - probably a more direct way to injure the head due to less protection of the human body in general). It may also happen from a fall (still depends on the height and the type of ground - soft (grass) or hard (asphalt type)) and often by physical assaults (which can lead to the use of different weapons, even a screwdriver).

\subsection{Cranial Injury with a screwdriver}

As stated at the beginning of this study presentation, the main focus will be on the physical assaults, resulting with a cranial injury of the head (skull and brain) with a screwdriver. A screwdriver is a tool which often is used by construction companies, or even one can have it at home for fixing something [4]. Nevertheless, this statement does not ignore the fact that a screwdriver can and it is being used as a weapon for direct assaults and the most common injury is the head (skull and brain) injury.

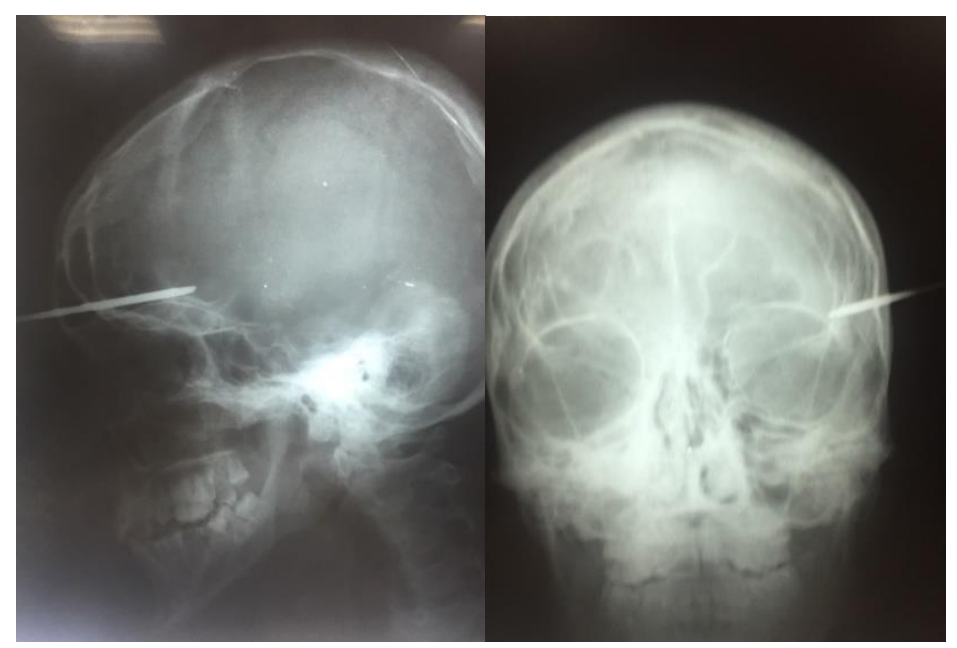

To make this more clear, there are a variety of head injuries which can be activated by an undesirable physical contact and / or can further lead to the underdevelopment of the brain itself, causing the malfunction of the human body or some parts of it (organ(s) malfunction) [4]. 
The (most common) major types of a head injury are (listed below):

- Hematoma

- Hemorrhage

- Concussion

- Edema

- Skull Fracture

\section{CASE Report (Prishtina, Kosovo)}

At the University Clinical Center in Prishtina Kosovo, in one of the neurological clinics, a rare case has been operated. The patient was admitted to the Emergency Center in Pristina around 15:00 in the afternoon, from a regional part of Kosovo where the injury occurred. The patient in admission was in a state of mind with partial communication and blend of words. Objectively the metal tool penetrated into the endocardium in the left frontal region. It is realized the brain CT, where is seen the metal tool known as a screwdriver, which had penetrated the shaft and was up to the breccia area (a clear reason why the patient started to lose speech). The patient is urgently prepared for operation, including general anesthetic surgery. An operator intervention is performed by the caregiver's neurosurgeon by opening a small craniotomy around the traumatic lesions and carefully penetrating the brain tissue up to the tip of the traumatic brain tract.
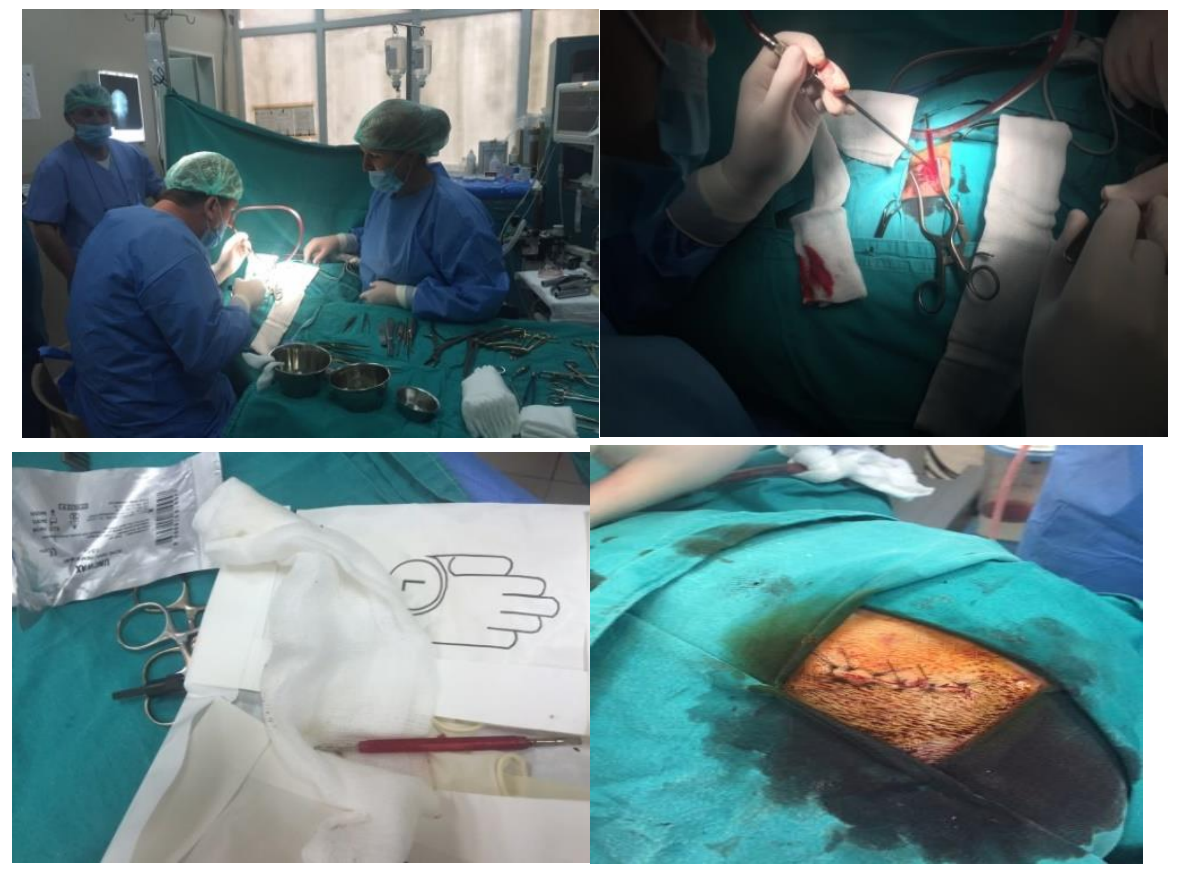


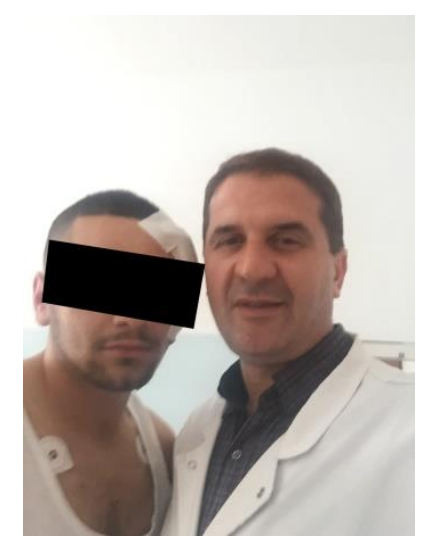

It is possible to successfully leave the metal tool. Correct hemostasis of the brain becomes minimal invasive bleeding. The operation ends within one hour. After the operation, the patient has only shown signs of neurological improvement, where he returns full speech / communication abilities very fluently. After a few hours the patient can also control body movements such as standing up, hands movements, headaches, walking right, and non-passive speech. Finally, after about 24 hours, a control brain CT is performed, which presents without any bleeding in the head of the patient in question. This is the first and rare case in UCCK, which has been treated professionally and successfully by taking into account the rapid reaction of the moment of hospital administration, where within an hour everything ends. It is worth mentioning that the nodular deficit manifested by the sensomotoric defect has been eliminated after the operation and the patient returns to normal neurological conditions.

Note: The case occurred in 2017 (27 April)

\section{Similar Case Report from United Kingdom (UK)}

Such cases are reportedly to happen also around the world, due to different type of attacks [5]. One of the countries that particularly shares such case reports is United Kingdom. Cranial Injuries with a screwdriver tend to happen very often and not only between adults $(+18$ and beyond), but also to children and teenagers as well, which can lead to a more difficult case (surgery) to be solved [5]. An attack with the screwdriver can lead to major infections as well. A similar Case report happened in United Kingdom (UK), where a 26 year old man was sent to emergency due to an angry assault from someone else. After the surgery he was discharged home, however the other day the man came back since he had a very strong headache and his confusion started to increase. Apparently he had an intracranial hemorrhage in the parietal lobe. After that and the needed care, he was sent back home after 17 days in the rehabilitation unit in the hospital.

It is of high importance that such cases are required to be notified earlier because the infection(s) may lead to other difficulties and make the case even worse. It is stated that "such case is a reminder of the need for a high index of suspicion in intoxicated head injured patients in whom the diagnosis of intracranial injuries is often delayed" (Tutton, et al. 1).

Moreover, cranial injuries with a screwdriver or otherwise known and presented as penetrating screwdriver, such wounds seem to be very unusual and less introduced in the literature and neurosurgical practice [6]. Additionally, screwdriver is one of the least tools to be used as a weapon and trying to penetrate with it into someone's head. Although, the damage may be very serious and cause severe injuries in the head and most importantly touch the brain. 


\section{Conclusion}

The safety of the human body especially the upper portion of it should be a must in our everyday life, due to the fact that the human head contains the most important organ, the brain, which in fact, does control our movements, thinking, and processing information and so on. It is consisted of three lobes: Frontal, Parietal and Occipital lobe.

The case report section is a great example of a cranial injury that happened in Prishtina, Kosovo, which is considered a rare case due to the fact that the injury was done with a screwdriver. The neurosurgeon tried to keep the health of the brain while removing the tool made out of metal and after the successful operation a control CT endocranion was performed and resulted that the patient was fine and able to communicate better than before the operation. It is very important to re-state the fact that body movements of the patient were improved within a very short time, since after the one-hour surgery and a little rest, he was able to walk and talk, controlling hand movements, head movements and trying to keep a non-passive communication with the doctors. 


\section{References}

1. Haas LF (December 2001). "Phineas Gage and the science of brain localisation". Journal of Neurology, Neurosurgery, and Psychiatry. 71 (6): 761.

2. “Head Injury: Types, Causes, and Symptoms.” Healthline, Healthline Media,

Retrieved from: www.healthline.com/health/head-injury.

3. Kuppermann N, Holmes JF, Dayan PS, Hoyle JD, Atabaki SM, Holubkov R, et al. (October 2009). "Identification of children at very low risk of clinically-important brain injuries after head trauma: a prospective cohort study". Lancet. 374 (9696): 1160-70.

4. Powell T (2004). Head Injury: A Practical Guide (2nd ed.). United Kingdom: Speech mark publishing Ltd. ISBN 978-0-86388-451-1.

5. "Traumatic Brain Injury (TBI)", SpringerReference, Springer-Verlag.

6. Tutton, Matthew G, et al. "Screwdriver Assaults and Intracranial Injuries." Emergency Medicine Journal, British Association for Accident and Emergency Medicine, 1 May 2000. 